\title{
Experiment assessment of mass effects in the rat: implications for small animal PET imaging
}

\author{
E. M. Jagoda ${ }^{\mathrm{a}}$, J. J. Vaquero ${ }^{\mathrm{b}}$, J. Seidel ${ }^{\mathrm{b}}$, M.V. Green ${ }^{\mathrm{b}}$, W.C. Eckelman ${ }^{\mathrm{a}, *}$ \\ ${ }^{a}$ PET Dept., Warren Grant Magnuson Clinical Center, Bethesda, MD 20892-1180, USA \\ ${ }^{\mathrm{b}}$ Department of Nuclear Medicine, National Institutes of Health, Bethesda, MD 20892, USA
}

\begin{abstract}
In vivo imaging using positron emission tomography (PET) is important in the development of new radiopharmaceuticals in rodent animal models for use as biochemical probes, diagnostic agents, or in drug development. We have shown mathematically that, if small animal imaging studies in rodents are to have the same "quality" as human PET studies, the same number of coincidence events must be detected from a typical rodent imaging "voxel" as from the human imaging voxel. To achieve this using the same specifi activity preparation, we show that roughly the same total amount of radiopharmaceutical must be given to a rodent as to a human subject. At high specifi activities, the mass associated with human doses, when administered to a rodent, may not decrease the uptake of radioactivity at non saturable sites or sites where an enzyme has a high capacity for a substrate. However, in the case of binding sites of low density such as receptors, the increased mass injected could saturate the receptor and lead to physiologic effects and non-linear kinetics. Because of the importance of the mass injected for small animal PET imaging, we experimentally compared high and low mass preparations using ex vivo biodistribution and phosphorimaging of three compounds: 2-fluoro-2-deoxyglucos (FDG), 6-fluoro-L-metatyrosin (FMT) and one receptor-directed compound, the serotonin $5 \mathrm{HT}_{1 \mathrm{~A}}$ receptor ligand, trans-4-fluoro-N-\{2-[4-(2-methoxylphenyl piperazino]ethyl $\}-\mathrm{N}-(2-$ pyridyl) cyclohexane- carboxamide (FCWAY). Changes in the mass injected per rat did not affect the distribution of FDG, FMT, and FCWAY in the range of $0.6-1.9 \mathrm{nmol}$ per rat. Changes in the target to nontarget ratio were observed for injected masses of FCWAY in the range of $\sim 5-50 \mathrm{nmol}$ per rat. If the specifi activity of such compounds and/or the sensitivity of small animal scanners are not increased relative to human studies, small animal PET imaging will not correctly portray the "true" tracer distribution. These difficultie will only be exacerbated in animals smaller than the rat, e.g., mice.
\end{abstract}

Keywords Animal imaging; PET; FDG; FMT; FCWAY

\section{Introduction}

The driving force for the development of small animal PET scanners is threefold: the availability of various disease models presently available in small animals, the advantage of paired statistics when using serial imaging compared to serial autopsy, and the need to replace, reduce, and refin animal use [1]. Most of the animal models of neurological disease [2], cardiovascular disease [3], and cancer [4] are in rodents. The choice of the animal species is determined by the general knowledge of the neuroanatomy and neurochemistry, the ability to investigate behavioral responses and the cost to purchase and house the species. Rats and mice meet many of these conditions.

PET radiopharmaceuticals fall into three categories: (1) those that trace nonsaturable systems (e.g. $\left[{ }^{18} \mathrm{~F}\right]$ fluorid in bone), (2) intermediate saturable systems (e.g., 2- $\left[{ }^{18} \mathrm{~F}\right]$ fluoro-2-deoxyglucos (FDG) to measure changes in glucose transporter (GLUT) and hexokinase activity, and 6- $\left[{ }^{18} \mathrm{~F}\right]$ fluoro-metatyrosin (FMT) to measure dopamine metabolism), and (3) easily saturable, low-density systems (e.g., $\left[{ }^{18} \mathrm{~F}\right]$ labeled FCWAY, a 5-HT ${ }_{1 \mathrm{~A}}$ antagonist to measure changes in 5- $\mathrm{HT}_{1 \mathrm{~A}}$ receptor density). Another example of the latter case is $\left[{ }^{18} \mathrm{~F}\right]$ labeled dVIP, a radioligand to measure VIP receptor density in tumors [5].

These three classes of radiopharmaceuticals present increasing imaging challenges as the density of the target site decreases. If we assume that studies are performed in humans with minimal saturation of the target sites at the attainable specifi activity, we can mathematically deduce the conditions necessary to obtain comparable images in rodents and then experimentally test the effect of these conclusions in rats using the three classes of radiopharma- 
Table 1

Properties of the compounds used for dissection studies.

\begin{tabular}{llcc}
\hline Radiopharmaceuticals & $\begin{array}{l}\mathrm{mCi} \\
\text { injected }\end{array}$ & $\begin{array}{l}\text { Specif c } \\
\text { activity } \\
\text { Ci/mmol* }\end{array}$ & $\begin{array}{l}\text { nmol } \\
\text { injected }\end{array}$ \\
\hline $2-\left[{ }^{18}\right.$ F]FDG & 4 & $\sim 1,000$ & 4 \\
$2-\left[{ }^{14} \mathrm{C}\right]$ FDG & 0.050 & $\sim 0.3$ & 167 \\
$2-\left[{ }^{18} \mathrm{~F}\right]$ FDG & 0.050 & $\sim 1000$ & 0.02 \\
$2-\left[{ }^{14} \mathrm{C}\right]$ FDG & 0.050 & $\sim 0.3$ & 167 \\
$6-\left[{ }^{18} \mathrm{~F}\right]$ FMT with carbidopa & 0.050 & 0.49 & 102 \\
{$\left[{ }^{18} \mathrm{~F}\right]$ FCWAY } & 0.050 & 869 & 0.089 \\
\hline
\end{tabular}

$*$ TOI $=$ time of injection.

ceuticals. We show with a simple mathematical argument that comparable images are obtained only when the amount of radioactivity administered to the rat is roughly the same as to the human. Thus, we compared biodistribution data in rats obtained with milliCurie, or human, level doses of injected tracer (by autoradiography) to microCurie amounts of injected tracer (by dissection and well counting) to identify potential violations of the tracer principal within these classes. Studies using PiPET were also performed to show that comparable images can be obtained in the rat brain [6].

\section{Materials and methods}

\subsection{Radiopharmaceuticals}

The $\left[{ }^{18} \mathrm{~F}\right]$ f uoride was taken directly from the ${ }^{18} \mathrm{O}$ target after proton irradiation and dissolved in phosphate buffer. The 2- $\left[{ }^{18} \mathrm{~F}\right] \mathrm{FDG}$ was prepared by the Hamacher method [7]. The $6-\left[{ }^{18} \mathrm{~F}\right]$ FMT was prepared following the publication of Namavari et al. [8]. To block aromatic amino acid decarboxylase (AAAD), carbidopa $(5 \mathrm{mg} / \mathrm{kg})$ was administered s.c. $30 \mathrm{~min}$ before $6-\left[{ }^{18} \mathrm{~F}\right] \mathrm{FMT}$. The trans- $\left[{ }^{18} \mathrm{~F}\right] \mathrm{FCWAY}$ was prepared by the method of Lang et al. [9].

\subsection{Rat biodistribution studies}

Adult male Sprague-Dawley rats $(200-250 \mathrm{~g})$ were injected intravenously with either $2-\left[{ }^{18} \mathrm{~F}\right] \mathrm{FDG}$ or trans$\left[{ }^{18} \mathrm{~F}\right] \mathrm{FCWAY}$ and intra-peritoneally with $6-\left[{ }^{18} \mathrm{~F}\right] \mathrm{FMT}$ (preinjected with carbidopa as described above) (Table 1). The rats were sacrif ced at times between 30 and 45 min postinjection of the F-18 labeled radiopharmaceutical and the brain was immediately placed in $0.3 \mathrm{M}$ sucrose on ice. The brain was dissected on ice; the blood and various brain tissues were collected and weighed. The radioactive content of the blood and various tissues was assayed by gamma counting. Reported ratios were obtained using the DUR values (differential uptake ratio is \%injected dose/g of target tissue $\times$ body weight $(\mathrm{g}) / 100)$.
Table 2

Properties of the compounds used for autoradiography.

\begin{tabular}{llcr}
\hline Radiopharmaceuticals & $\begin{array}{l}\mathrm{mCi} \\
\text { injected }\end{array}$ & $\begin{array}{l}\text { Specif c } \\
\text { activity } \\
\mathrm{Ci} / \mathrm{mmol}^{*}\end{array}$ & $\begin{array}{l}\mathrm{nmol} \\
\text { injected }\end{array}$ \\
\hline $2-\left[{ }^{18} \mathrm{~F}\right]$ FDG & 4 & $\sim 1,000$ & 4 \\
$6-\left[{ }^{18} \mathrm{~F}\right]$ FMT with carbidopa & 3 & 0.60 & 5,000 \\
{$\left[{ }^{18} \mathrm{~F}\right] \mathrm{FCWAY}$} & 1 & 1266 & 1.0 \\
\hline
\end{tabular}

$*$ TOI $=$ time of injection.

\subsection{Rat ex vivo autoradiography and data analysis}

Adult male Sprague-Dawley rats $(200-250 \mathrm{~g})$ were injected intravenously with the amount of radiopharmaceutical listed in Table 2 and sacrif ced after $30 \mathrm{~min}$. The carbidopa was pre-injected as described previously. The brains were removed, immediately quick frozen in dry ice, and cut into $20 \mu \mathrm{m}$ slices using a BIHI cytomicrotome (Bright Instrument Co. and Hacker Instrument Inc, B2589). The slices were placed on slides, air dried, and placed on a phosphorimaging plate with a pixel size of $25 \mu \mathrm{m}^{2}$ (Fuji BAS-SR2025). After exposure the plates were scanned using a Fuji Bio-imaging Analysis System 5000. These plates have a high cross section for beta particles and relatively low cross section for gamma rays.

The quantitative data expressed as differential uptake ratio $/ \mathrm{m}^{2}$ of target tissue (DUR $/ \mathrm{m}^{2}$ ) were determined by correlating $\mathrm{cpm}$ to PSL (photo-stimulated luminescence units). For each study adjacent brain slices at 6 different regions throughout the brain were used to determine the linear relationship of PSL to $\mathrm{cpm}(\mathrm{cpm}=$ slope $\times$ PSL $)$. One slice was exposed to the phosphorimaging plate overnight and the adjacent slice was counted on a 1480 Wallac Wizard gamma counter. Using the PSL units associated with the phosphorimaging slice and the cpm from the adjacent slice, the slope of the line was determined for each study (the slope varied from $0.169-0.192$ between studies). Using this relationship, regions of interest could be converted from $\mathrm{PSL} / \mathrm{m}^{2}$ to $\mathrm{cpm} / \mathrm{m}^{2}$, which was used to calculate DUR $/ \mathrm{m}^{2}$ by the following equation:

$$
\text { DUR } / \mathrm{m}^{2}=\frac{\left(\mathrm{cpm} / \mathrm{m}^{2}\right) \times(\text { body weight }(\mathrm{g}))}{\mathrm{cpm} \text { injected } \times 100}
$$

The area of interest on the phosphor plate was not multiplied by the slice thickness of $20 \mu \mathrm{m}$ to give a measure of radioactivity per volume because of the additional assumptions concerning the eff ciency of collecting positron decay at different depths.

\subsection{Imaging using PiPET}

As an adjunct to the in vitro measurements, we performed imaging studies in a group of rats using the PiPET (6) small animal PET imaging system, PiPET is comprised 
Table 3

Properties of radiopharmaceuticals used for PiPET imaging.

\begin{tabular}{llllr}
\hline Radiopharmaceuticals & $\begin{array}{l}\text { Sacrif ce } \\
\text { time } \\
(\mathrm{min})\end{array}$ & $\begin{array}{l}\mathrm{mCi} \\
\text { injected }\end{array}$ & $\begin{array}{l}\text { Specif c } \\
\text { activity } \\
\mathrm{Ci} / \mathrm{mmol}^{*}\end{array}$ & $\begin{array}{l}\text { nmol } \\
\text { injected }\end{array}$ \\
\hline$\left[{ }^{18} \mathrm{~F}\right] \mathrm{f}$ uoride & 120 & 1 & $\sim 1,000$ & 1 \\
$2-\left[{ }^{18} \mathrm{~F}\right]$ FDG & 45 & 4 & $\sim 1,000$ & 4 \\
6- $\left[{ }^{18} \mathrm{~F}\right]$ FMT with carbidopa & 45 & 4.4 & 0.70 & 6,298 \\
{$\left[{ }^{18} \mathrm{~F}\right] \mathrm{FCWAY}$} & & & & \\
$\quad$ Brain only & 30 & 2.0 & 3,283 & 0.6 \\
\hline
\end{tabular}

$*$ TOI $=$ time of injection.

of two opposed bismuth germanate (BGO) detector modules $20-\mathrm{cm}$ apart and operated in time coincidence. Each detector consists of a $26 \times 22$ array of $2 \mathrm{~mm} \times 2 \mathrm{~mm} \times 10 \mathrm{~mm}$ long BGO crystals coupled with optical grease to the face of a Hamamatsu R3941 position-sensitive photomultiplier tube (PSPMT). Each crystal is polished on f ve sides and f nely ground on its entrance end. All crystals are double-wrapped on their long sides with PTFE tape including the entrance end. The f eld-of-view of PiPET is $55 \mathrm{~mm}$ (transverse) $\times 45$ $\mathrm{mm}$ (axial).

Tomographic imaging is performed by attaching the object to be imaged to a vertical rotation stage placed midway between the detectors. During data acquisition, the object is rotated continuously around this vertical axis to acquire all possible lines-of-response. Tomographic images are then reconstructed from lines that fall within a user-selected range of angles relative to the detector normals. The absolute central point source sensitivity of PiPET is $130 \mathrm{cps} / \mu \mathrm{Ci}$ with an isotropic reconstructed spatial resolution of $2.1 \mathrm{~mm}$ (FWHM) using fltered back-projection and ramp flter. Images shown in this report were reconstructed with the 3D OSEM resolution recovery algorithm (20 iterations) rather than FBP. Spatial resolution in these images is estimated at $1.5 \mathrm{~mm}$. This scanner and its use have been described previously [6].

\subsection{Rat PiPETstudies and data analysis}

Adult male Sprague-Dawley rats $(200-250 \mathrm{~g})$ were injected with the amount of the ${ }^{18} \mathrm{~F}$ labeled radiopharmaceu- ticals and sacrif ced at the times shown in Table 3. The animal was then attached to the rotation device so that the upper half of the animal was in the feld-of-view and imaging begun. In the $6-\left[{ }^{18} \mathrm{~F}\right] \mathrm{FMT}$ studies the rats were injected with carbidopa (s.c. $5 \mathrm{mg} / \mathrm{kg}$ ) $30 \mathrm{~min}$ prior to the $6-\left[{ }^{18} \mathrm{~F}\right] \mathrm{FMT}$.

Target-to-non-target ratios were obtained from the PiPET images in each of these cases by def ning three separate regions-of-interest in the target region and three in the reference region of each image. The regions were well within the borders of the chosen tissue. Ratios were computed from the average of the target values divided by the average of the non-target values. Each ratio represents the ratio from a single animal.

\section{Results}

Since a reference tissue is not available for $2-\left[{ }^{18} \mathrm{~F}\right] \mathrm{FDG}$ and gray to white ratios are diff cult to obtain, ratios of brain tissue to cerebellum for co-injected $\left[{ }^{14} \mathrm{C}\right] \mathrm{FDG}$ and $2-\left[{ }^{18} \mathrm{~F}\right] \mathrm{FDG}$ in rats were obtained by autoradiography and biodistribution studies (Table 4). The ratios were found to be similar whether the images were obtained using autoradiography with $50 \mu \mathrm{Ci}\left[{ }^{14} \mathrm{C}\right] \mathrm{FDG}$ or $4 \mathrm{mCi}$ of $2-\left[{ }^{18} \mathrm{~F}\right] \mathrm{FDG}$ (Table 4). Comparison of the ratios of the biodistribution studies using co-injected $10 \mu \mathrm{Ci}\left[{ }^{14} \mathrm{C}\right] \mathrm{FDG}$ or $100 \mu \mathrm{Ci}$ of $2-\left[{ }^{18} \mathrm{~F}\right] \mathrm{FDG}$ were also similar although the absolute ratios had a higher trend. Since the injected mass of FDG is small compared to the concentration found in plasma $(5 \mathrm{mM})$ and given the capacity of the glucose transporters (GLUT) and the velocity of hexokinase phosphorylation, this is not unexpected (see Sec. 4). The single distribution point is justif ed based on previous studies showing that the radioactivity in the brain is FDG 6-phosphate at this time point.

The mass effect of FCWAY and FMT was established over the range of 50 to $200 \mathrm{nmol}$ per rat for FCWAY and 57 to $5645 \mathrm{nmol}$ per rat for FMT (Tables 5 and 6). These data show that, at 50 and $200 \mathrm{nmol} / \mathrm{rat}$ WAY100635, binding is decreased signif cantly in the tissues studied, whereas FMT binding is not decreased over the experimental range.

Quantitation of 2-[ $\left[{ }^{18} \mathrm{~F}\right] \mathrm{FDG}, 6-\left[{ }^{18} \mathrm{~F}\right] \mathrm{FMT}$, and trans$\left[{ }^{18} \mathrm{~F}\right] \mathrm{FCWAY}$ was carried out using autoradiography (Fig. $1 \mathrm{~b}-1 \mathrm{~d})$ and ex vivo counting of dissected rat brain and ratios

Table 4

Ratios of rat regional brain uptake to cerebellum (CB) for $\left[{ }^{18} \mathrm{~F}\right] \mathrm{FDG}$ and $\left[{ }^{14} \mathrm{C}\right] \mathrm{FDG}$ (coinjected) determined by biodistribution and autoradiography at 30 min.

\begin{tabular}{lclllll}
\hline & Dose $(\mu \mathrm{Ci})$ & Cortex $/ \mathrm{CB}$ & Caudate/CB & Thalamus/CB & Hippocampus/CB & Brain stem/CB \\
\hline$\left[{ }^{18}\right.$ F $]$ FDG & 100 & $\mathbf{1 . 3 7} \pm \mathbf{0 . 0 5} *$ & $\mathbf{1 . 4 6} \pm \mathbf{0 . 0 9}$ & $\mathbf{1 . 2 6} \pm \mathbf{0 . 0 4}$ & $1.03 \pm 0.03$ & $0.98 \pm 0.03$ \\
{$\left[{ }^{14} \mathrm{C}\right]$ FDG } & 10 & $\mathbf{1 . 4 3} \pm \mathbf{0 . 0 2} *$ & $\mathbf{1 . 5 4} \pm \mathbf{0 . 0 8}$ & $\mathbf{1 . 2 8} \pm \mathbf{0 . 0 2}$ & $1.05 \pm 0.04$ & $0.99 \pm 0.04$ \\
{$\left[{ }^{18}\right.$ F $]$ FDG } & 4000 & $\mathbf{1 . 6 2} \pm \mathbf{0 . 0 7}$ & $\mathbf{1 . 6 9} \pm \mathbf{0 . 0 9}$ & $\mathbf{1 . 4 8} \pm \mathbf{0 . 1 5}$ & $1.14 \pm 0.10$ & $1.29 \pm 0.20$ \\
{$\left[{ }^{14} \mathrm{C}\right]$ FDG } & 50 & $\mathbf{1 . 6 1} \pm \mathbf{0 . 0 7}$ & $\mathbf{1 . 6 5} \pm \mathbf{0 . 1 0}$ & $\mathbf{1 . 4 7} \pm \mathbf{0 . 1 1}$ & $1.19 \pm 0.03$ & $1.24 \pm 0.21$ \\
\hline
\end{tabular}

Values in bold are signif cantly different from one $(p<0.05)$

* Represents the mean ratio \pm SD by biodistribution; $n=5$. 
Table 5

Mass effect on trans- $\left[{ }^{18} \mathrm{~F}\right] \mathrm{FCWAY}$ distribution (DUR) in rat brain.

\begin{tabular}{lrrr}
\hline$\left.{ }^{18} \mathrm{~F}\right] \mathrm{FCWAY}$ & \multicolumn{1}{c}{ Cortex } & Hippocampus & Caudate \\
\hline $\mathrm{NCA}^{*}$ & $2.01 \pm 0.360$ & $3.05 \pm 0.422$ & $0.160 \pm 0.033$ \\
$+50 \mathrm{nmol}^{\dagger}$ & $0.564 \pm 0.031$ & $1.48 \pm 0.141$ & $0.272 \pm 0.064$ \\
$+200 \mathrm{nmol}^{\dagger}$ & $0.217 \pm 0.036$ & $0.267 \pm 0.040$ & $0.137 \pm 0.020$ \\
\hline
\end{tabular}

Values represent the mean DUR $\pm \mathrm{SD}, \mathrm{n}=5$. The raw data are taken from Lang et al. J Med Chem. 1999 (9) and transformed to DUR values to correct for differences in animal weights.

* No-carrier-added.

${ }^{\dagger}$ Mass of WAY 100635 coinjected.

obtained for these three radiopharmaceuticals (Table 7). Tissues containing very low concentrations of receptor were used as a reference region.

FDG gave similar ratios using the two methods of analysis (Table 7). When $5 \mathrm{mg} / \mathrm{kg}$ carbidopa was injected before $6-\left[{ }^{18} \mathrm{~F}\right] \mathrm{FMT}$, the uptake in the striatum of the rat was clearly visualized. The ratio of uptake in the caudate to cerebellum was 1.7 using autoradiography. The ratio obtained by injecting $1 / 60$ of the dose used in the imaging experiment and analyzing tissue radioactivity by gamma counting was also 1.7 at $45 \mathrm{~min}$ after injection (Table 8). The cerebellum is used as a reference tissue to normalize the study across experiments. The ratio in the target site of interest, the caudate, is the same in both experiments showing that at these mass differences, no mass effects were observed.

For trans- $\left[{ }^{18} \mathrm{~F}\right] \mathrm{FCWAY}$, the hippocampus to cerebellum ratios obtained using biodistribution was 20 , respectively while the hippocampus to cerebellum ratio was 19 by autoradiography (Table 7). Although the primary comparison in this study was between the low dose biodistribution studies and the high dose autoradiography studies, PiPET imaging was also carried out. PiPET images of the distributions of $\left[{ }^{18} \mathrm{~F}\right] \mathrm{f}$ uoride, 2-[ $\left[{ }^{18} \mathrm{~F}\right] \mathrm{FDG}, 6-\left[{ }^{18} \mathrm{~F}\right] \mathrm{FMT}$, and trans- $\left[{ }^{18} \mathrm{~F}\right] \mathrm{FCWAY}$ in the rat head and brain are shown in Figs. 1a-1d. Since the binding of $\mathrm{f}$ uoride by bone is known to be a non-saturable process, comparison with ex vivo autoradiography was not carried out. The very high targetto-non-target ratios, evident in the bone scan of the head, are virtually identical to those observed in the $\mathrm{CT}$ scan of the same animal (Fig 1a). PiPET images of $2-\left[{ }^{18} \mathrm{~F}\right] \mathrm{FDG}$, $6-\left[{ }^{18} \mathrm{~F}\right] \mathrm{FMT}$, and trans- $\left[{ }^{18} \mathrm{~F}\right] \mathrm{FCWAY}$ in the brain, shown in Figs. 1b-1d, gave similar ratios as those found by autoradiography although these were obtained from the average of three determinations in a single animal (data not shown).
PiPET has been used in small animal studies and found to be quantitative and of suff cient resolution for imaging dendritic cell migration [10], liver metabolism [11], and adrenal tumors [12].

\section{Discussion}

Many studies on allometry suggest that the radiopharmaceutical injection be scaled either by the body weight or by the body surface area [13]. Many simple biological processes carried out in different species can be understood on the basis of these relationships. Thus, if weights were used as the allometric factor, the radioactivity injected into a rat would be scaled down by $\sim 0.25 \mathrm{~kg} / 70 \mathrm{~kg}=1 / 280$. With this calculation, the dose injected into a rat to maintain the same percentage saturation would be $\sim 0.4 \%$ of the human dose. If the resolution of the PET scanner required for animal brains were no greater than that required for humans $(\sim 5 \mathrm{~mm})$, this amount would be appropriate. However, that is clearly not the case.

It can be shown that although body weight scaling is appropriate if drug concentrations are to be the same in both human and animal, PET imaging in various species of different size requires a different relationship (Appendix I). If we wish to visualize the rat brain with the same relative acuity as we visualize the human brain, the volume of the resolution voxel in the rat must be shrunk approximately in proportion to the animal's mass relative to the human mass (1/280). Moreover, if a rat and human PET study are to be "equivalent" from an imaging point of view, the same coincidence rate must be observed from a rat resolution voxel as from a human resolution voxel. It follows, therefore, that the increase in dose with increasing resolution and the

Table 6

Mass effect on 6- $\left[{ }^{18} \mathrm{~F}\right] \mathrm{FMT}$ distribution (DUR) in rat brain.

\begin{tabular}{lllll}
\hline$\left[{ }^{18} \mathrm{~F}\right] \mathrm{FMT}$ & Caudate & Thalamus & Cerebellum & Cortex \\
\hline $57 \mathrm{nmol}^{*}$ & $0.724 \pm 0.071$ & $0.470 \pm 0.047$ & $0.399 \pm 0.068$ & $0.410 \pm 0.048$ \\
$597 \mathrm{nmol}^{*}$ & $0.667 \pm 0.119$ & $0.476 \pm 0.079$ & $0.388 \pm 0.057$ & $0.399 \pm 0.083$ \\
$5645 \mathrm{nmol}^{*}$ & $0.765 \pm 0.119$ & $0.555 \pm 0.057$ & $0.458 \pm 0.050$ & $0.410 \pm 0.057$ \\
\hline
\end{tabular}

Values represent the mean DUR $\pm \mathrm{SD}, n=4-5$.

* Mass associated with $\left[{ }^{18} \mathrm{~F}\right] \mathrm{FMT}$ injected. 

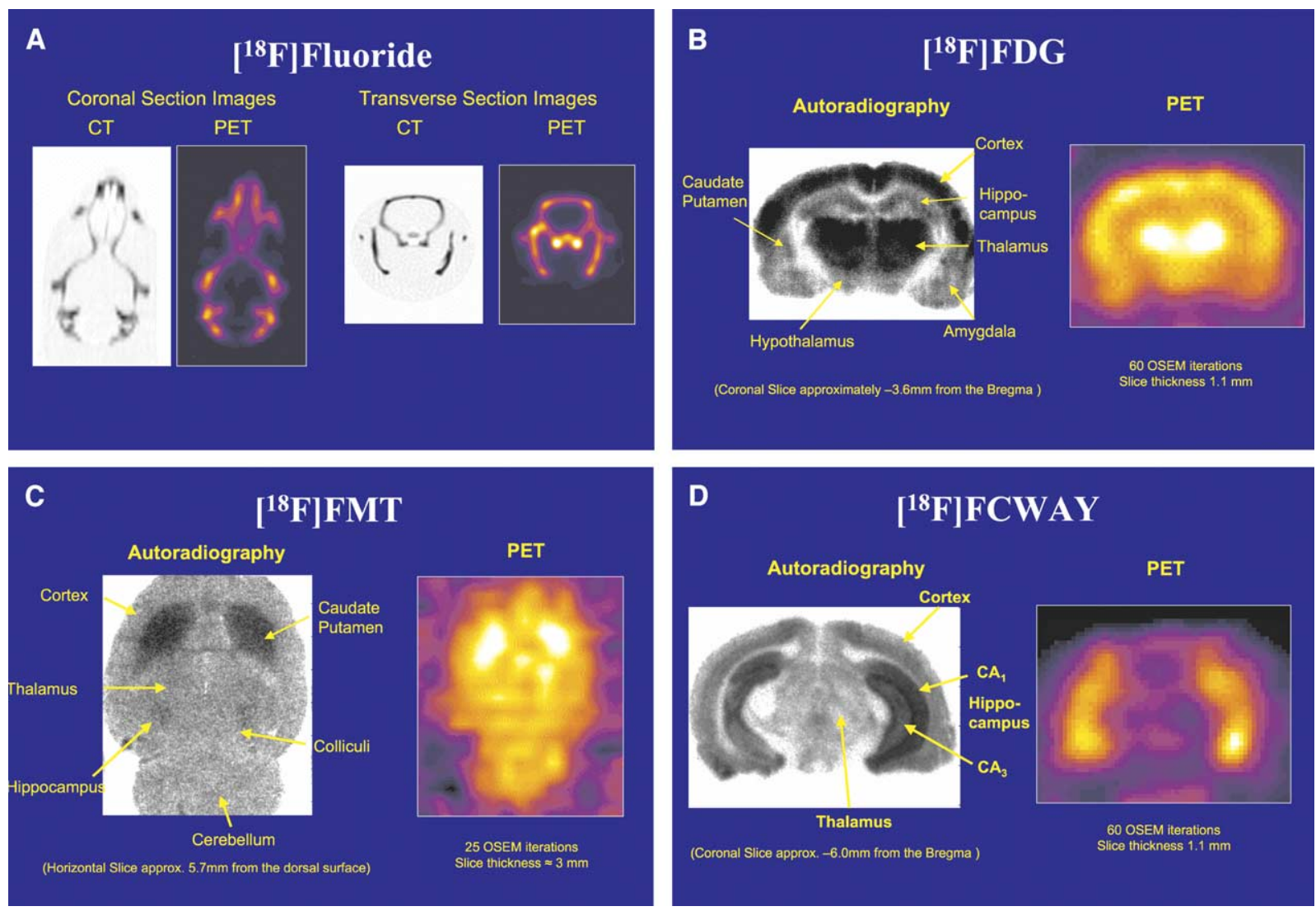

Fig. 1. Comparison of images of the rat head obtained by PET (right panels) in approximate spatial registration with images obtained by other methods in different animals (left panels): (A) CT versus F-18 f uoride-transverse section, (B) autoradiography versus F-18 FDG-transverse section, (C) autoradiography versus F-18 FMT-coronal section and (D) autoradiography versus F-18 FCWAY-transverse section. See Table 3 for details on the radiopharmaceutical dose.

decrease in dose with decreasing body weight cancel one another and the amount of tracer we must administer to the rat is about the same as to the human. It also follows that if a rat receives this human tracer dose, the concentration of drug in the animal will be higher in the ratio of human to rat body mass, potentially saturating vulnerable systems (the above argument ignores differences in attenuation, detection eff ciency but which are included in the Appendix). Similar arguments can be made for brain imaging where the ratio in mass between humans and rat is approximately 1,000 .

In humans, nonsaturable sites (e.g. $\left[{ }^{18} \mathrm{~F}\right] \mathrm{f}$ uoride in bone) and intermediate saturable sites (e.g., 2-[ $\left.{ }^{18} \mathrm{~F}\right] \mathrm{FDG}$ to mea- sure GLUT and hexokinase activity or $6-\left[{ }^{18} \mathrm{~F}\right] \mathrm{FMT}$ ) are not affected by low specif $\mathrm{c}$ activities or large injected masses. No report of an effect of specif $\mathrm{c}$ activity using $\left[{ }^{18} \mathrm{~F}\right] \mathrm{f}$ uoride is reported and the United States Pharmacopoeia proposes the use of 2-[ $\left.{ }^{18} \mathrm{~F}\right] \mathrm{f}$ uoro-2-deoxyglucose at specif $\mathrm{c}$ activities as low as $1 \mathrm{Ci} / \mathrm{mmol}$ for a $10 \mathrm{mCi}$ dose of FDG. However, in easily saturated processes such as the binding of radiotracers to receptors, specif c activity plays an important part.

In general, to avoid physiologic effects in the tracer study and to avoid decreasing the target to non-target ratio significantly, the receptor saturation should be below 5\%. This can be seen from the equilibrium equation for binding attributed to Scatchard

Table 7

Tissue ratios obtained by phosphorimaging compared to dissection data.

\begin{tabular}{llcc}
\hline Radiopharmaceuticals & Tissue ratio used & Biodistribution & Autoradiography \\
\hline$\left[{ }^{18}\right.$ F FDG & Caudate to cerebellum & $1.5 \pm 0.1^{*}$ & $1.7 \pm 0.1^{\dagger}$ \\
6- $\left[{ }^{\dagger}\right.$ F $]$ FMT with carbidopa & Caudate to cerebellum & $1.8 \pm 0.03^{*}$ & $1.7 \pm 0.1^{\dagger}$ \\
{$\left[{ }^{18}\right.$ F FCWAY brain only } & Hippocampus to cerebellum & $\mathbf{2 0 . 3} \pm \mathbf{2 . 2}$ & $\mathbf{1 9 . 1}^{\dagger} \mathbf{3 . 3}$ \\
\hline
\end{tabular}

Conditions given in Tables 1 and 2. Values in bold are signif cantly different from one $(p<0.05)$

* Mean ratio $\pm \mathrm{SD} ; n=5$.

Mean ratio $\pm \mathrm{SD} ; n=3$.

\#ean ratio $\pm \mathrm{SD} ; n=4$. 
Table 8

Ratio of tissue to cerebellum at $45 \mathrm{~min}$ after injection in rats at $0.050 \mathrm{mCi}$ (biodistribution) and $3 \mathrm{mCi}$ (autoradiography) of $6-\left[{ }^{18} \mathrm{~F}\right] \mathrm{FMT}$.

\begin{tabular}{lrlllrr}
\hline & $\begin{array}{l}\text { Dose } \\
(\mu \mathrm{Ci})\end{array}$ & Cortex & Caudate & Brain stem & Thalamus & Hippocampus \\
\hline$\left[{ }^{18} \mathrm{~F}\right] \mathrm{FMT}$ & 50 & $1.05 \pm 0.05^{*}$ & $\mathbf{1 . 6 9} \pm \mathbf{0 . 0 8}$ & $0.86 \pm 0.43$ & $1.16 \pm 0.03$ & $\mathbf{1 . 2 0} \pm \mathbf{0 . 0 5}$ \\
{$\left[{ }^{18} \mathrm{~F}\right] \mathrm{FMT}$} & 3000 & $1.02 \pm 0.04^{\dagger}$ & $\mathbf{1 . 8 4} \pm \mathbf{0 . 0 3}$ & $1.10 \pm 0.14$ & $1.15 \pm 0.01$ & $1.13 \pm 0.01$ \\
\hline
\end{tabular}

Values in bold are signif cantly different from one $(p<0.05)$.

* Represents the mean ratio $\pm \mathrm{SD} ; n=6$.

${ }^{\dagger}$ Represents the mean ratio $\pm \mathrm{SD} ; n=3$.

$$
B / F=\left(B_{\max }-B\right) / K_{D} \rightarrow \text { target to non-target ratio }
$$

where the bound concentration over the free concentration ratio $(B / F)$ is related to the equilibrium dissociation constant $\left(K_{D}\right)$ and the total receptor concentration $\left(B_{\max }\right)$.

Although the kinetic analysis would be affected by increased mass, mostly by invalidating the assumption of $\mathrm{f} \mathrm{rst}$ order kinetics used in most of the mathematical approaches, the single scan technique employed here will be affected as well. The $B / F$, which will be the bound concentration over the free concentration, is related to the maximum receptor concentration minus the bound concentration divided by the $K_{D}$ and therefore if the bound concentration is large compared to the maximum receptor concentration, the observable $B / F$ will be reduced. That equilibrium equation is the basis of why we have compared $B / F$ at different specif c activities and total mass injected. Although a mathematical approach to second order kinetics is clearly possible, the physiologic effects, as demonstrated by Bolo, et al. [15] for FDG, are something to be avoided in tracer experiments. Recent experiments with the muscarinic-2 receptor agonist, $\left[{ }^{18} \mathrm{~F}\right]$ FP-TZTP, have also shown the physiologic effect of low specif c activity studies [14].

If we now return to the examples of three classes of PET radiopharmaceuticals, we see that the uptake of $\left[{ }^{18} \mathrm{~F}\right] \mathrm{f}$ uoride in bone will not be affected if we inject 1000 times human dose per kilogram in a rat. However, the use of the human dose of $2-\left[{ }^{18} \mathrm{~F}\right] \mathrm{FDG}$ in rats may be more problematic if FDG is used at the USP limit of $1 \mathrm{Ci} / \mathrm{mmol}$. Since the specif $\mathrm{c}$ activity of FDG has been increased by $>1,000$ with the adoption of the Hamacher synthesis for FDG [7], the chemical dose of FDG should not approach the saturation level of the enzyme involved. Bolo et al. [15] in studying the metabolic trapping eff ciency of hexokinase in rabbit brain found that 70 and $210 \mathrm{mg} / \mathrm{kg}$ altered the pharmacokinetics in the brain compared to no-carrier-added $\left[{ }^{18} \mathrm{~F}\right]$ FDG. Bolo et al. [15] saw saturation at $0.38 \mathrm{mmol}(70$ $\mathrm{mg}) / \mathrm{kg}$ in rabbits. If saturation in rabbit brain is at $>0.38$ $\mathrm{mmol} / \mathrm{kg}$ and the maximal human dose is $140 \mathrm{nmol} / \mathrm{kg}$, then there is a safety factor of $\sim 2,700$ in the human brain. If $1000 \times$ the dose is injected in a rat, there will be a small safety factor using FDG prepared by electrophilic f uorination and a large safety factor for FDG prepared by the nucleophilic fuorination proposed by Hamacher et al. [7]. There has also been a series of studies using $\left[{ }^{19} \mathrm{~F}\right] \mathrm{FDG}$ in vivo. $\left[{ }^{19} \mathrm{~F}\right] \mathrm{FDG}$ is the NMR active, stable isotope of $\mathrm{fuo}-$ rine. In order to obtain a measurable spectra with $\left[{ }^{19} \mathrm{~F}\right] \mathrm{FDG}$ and $\left[{ }^{19} \mathrm{~F}\right] \mathrm{FDG}$ 6-phosphate, the investigators used between 150 and $200 \mathrm{mg}$ of $\left[{ }^{19} \mathrm{~F}\right] \mathrm{FDG} / \mathrm{kg}$. Physiologic effects were observed at $>200 \mathrm{mg} / \mathrm{kg}$. Although the effect of mass paralleled that found in the $\left[{ }^{18} \mathrm{~F}\right] \mathrm{FDG}$ studies, the uptake of $\left[{ }^{18} \mathrm{~F}\right] \mathrm{FDG}$ and $\left[{ }^{19} \mathrm{~F}\right] \mathrm{FDG}$ was decreased by the added mass and the pharmacokinetics were altered [16].

A similar argument can be made for $6-\left[{ }^{18} \mathrm{~F}\right] \mathrm{FMT}$, although it is prepared primarily using electrophilic fuorination at lower specif c activities of $0.5-20 \mathrm{Ci} / \mathrm{mmol}$. The capacity of the various enzymes in the metabolic pathway of FMT in the rat are high, e.g., the AAAD activity in rat plasma is $60 \mathrm{pmol} / \mathrm{min} / \mathrm{ml}$. Barrio et al. showed that even at $5 \mathrm{mg} / \mathrm{kg}$ carbidopa there was still peripheral AAAD metabolism [17]. They also showed that the rat striatum contained about half of the $6-\left[{ }^{18} \mathrm{~F}\right] \mathrm{f}$ uorotyramine found in the rat treated with carbidopa and very little 6-[ $\left.{ }^{18} \mathrm{~F}\right] \mathrm{FMT}$. The concentration of AAAD in the rat brain is very high, 106.7 $\mathrm{nmol} / \mathrm{min} / \mathrm{g}$ tissue [18]. In these situations where the radioligand is a substrate for a high capacity enzyme and the plasma concentration of amino acids is $\sim 5 \mathrm{mM}$, decreasing the uptake by saturating the target site is not likely. In fact, similar ratios of tissue to cerebellun (Table 8) was obtained with $\mu \mathrm{Ci}$ and $\mathrm{mCi}$ injections in rat for $6-\left[{ }^{18} \mathrm{~F}\right] \mathrm{FMT}$. This is true for substrates for enzymes and transporters; inhibitors of enzymes and transporters would have to be treated like receptor binding radiotracers because the enzyme does not act on the radiotracer in a catalytic manner.

In the case of receptor binding radiotracers, the use of a $1,000 \times$ radioactive dose per $\mathrm{kg}$ for brain scanning could saturate the receptor above the $5 \%$ level. The calculations of saturation level for receptor binding radiotracers is very dependent on relatively small changes in specif c activity, amount injected, and the percentage extracted by various brain regions [19]. For example, for trans- $\left[{ }^{18} \mathrm{~F}\right] \mathrm{FCWAY}$, the average $5-\mathrm{HT}_{1 \mathrm{~A}}$ receptor concentration in the rat hippocampus is $80 \mathrm{nM}$ [20]. With a $5 \mathrm{mCi}$ injection of $1000 \mathrm{Ci} / \mathrm{mmol}$ specif c activity at the time of injection, the mass injected would be $5 \mathrm{nmol}$. Based on the value of $1.3 \% \mathrm{ID} / \mathrm{g}$ observed in the rat hippocampus, the concentration in a homogeneous solution would be $65 \mathrm{nM}$. Taking the nonspecif c binding value of $0.06 \% \mathrm{ID} / \mathrm{g}$, the concentration of nonspecif $\mathrm{c}$ binding would be $3 \mathrm{nM}$. Comparing the bound concentration (65 $\mathrm{nM}$ ) with the hippocampal $B_{\max }$ of $80 \mathrm{nM}$ indicates that the hippocampal $5-\mathrm{HT}_{1 \mathrm{~A}}$ receptor would be close to saturation. 
A more rigorous calculation based on the equilibrium saturation binding with ligand depletion and assuming equal volumes of distribution indicates that the fraction of the total receptor occupied in the brain was 77\% [21]. Motulsky has published a formula where he includes nonspecif $\mathrm{c}$ binding [22]. This approach gave the same results in that the total receptor in the brain was near saturation. The $5-\mathrm{HT}_{1 \mathrm{~A}}$ receptor concentrations in rats are similar to those found in humans [23].

In the actual PiPET study performed with FCWAY (Table 3 ), the average specif c activity at time of injection was $3283 \mathrm{Ci} / \mathrm{mmol}$ and the amount injected was $2 \mathrm{mCi}$. The concentration of bound material using the same $\% \mathrm{ID} / \mathrm{g}$ in the hippocampus will be $0.6 \mathrm{nmol} \times 0.013 / \mathrm{g}$ or $8 \mathrm{nM}$. This represents $10 \%$ of the total hippocampal receptor concentration whereas the previous calculation represented $77 \%$ for a mass injection of $5 \mathrm{nmol}$. Calculations using the approach put forward by Selikson [21] and Motulsky [22] also gave an occupancy of $10 \%$. These calculations were based on a $K_{i}$ for FCWAY of $1 \mathrm{nM}$. In various in vitro tests, we have obtained $K_{i}$ values from 0.2 to $1 \mathrm{nM}$. Changing the $K_{i}$ from 1 to $0.2 \mathrm{nM}$ did not change the occupancy significantly. In the frst example, a $5 \mathrm{mCi}$ injection of 1000 $\mathrm{Ci} / \mathrm{mmol}(5 \mathrm{nmol})$ resulted in a calculated receptor saturation of $77 \%$. In the actual study, a $2 \mathrm{mCi}$ dose of 3304 $\mathrm{Ci} / \mathrm{mmol}$; $(0.6 \mathrm{nmol})$, the occupancy was reduced to $10 \%$. It is clear from these examples that relatively small changes in dose resulted in major changes in occupancy.

There are two cautionary notes. The ratio of hippocampus to cerebellum in the biodistribution studies were comparable with that obtained with autoradiography (Table 7). This may be the result of the ability to analyze a very distinct region of the hippocampus with autoradiography versus the entire structure used for the biodistribution study. We have compared the PSL units in the CA1 band with the average PSL in the entire hippocampus from the autoradiography studies and found a ratio of $\sim 5$ indicating that regional differences were large.

Furthermore, the equations used here and those used by Hume et al. [19] and Meikle et al. [24] are equilibrium equations and there is no indication that FCWAY is at steady state in all tissues at $30 \mathrm{~min}$ after injection although the net eff ux is similar in target tissue and metabolite corrected plasma [9]. In conclusion, small differences can change the percentage saturation substantially and experiments must be performed for each radiopharmaceutical at the injected dose and specif c activity.

Hume et al. have carried out theoretical calculations based on the properties of three compounds with varying aff nities for the limited number of target sites [19]. Hume et al. [19] show that in the range of dose observed for WAY 100635, the occupancy would be very dependent on the exact $\mathrm{ED}_{50}$ value. Meikle et al. [24] have made a similar argument, but concentrated on tomographic sensitivity using average values for brain uptake and specif c activities. Because small changes in aff nity and receptor concentra- tion have large effects on the occupancy, it is diff cult to project a rule of thumb for various compounds as discussed above.

\section{Conclusion}

In present day practice we are far from obtaining the theoretical specif $\mathrm{c}$ activity for ${ }^{18} \mathrm{~F}$ or ${ }^{11} \mathrm{C}$ radiopharmaceuticals. However, for nonsaturable sites or high capacity sites injecting a human dose into a rat should not affect the pharmacokinetics. For receptor binding radioligands, the present experimental specif $\mathrm{c}$ activities and the associated dose could lead to partial saturation of the target site in rats and more certainly in mice. An increase in the effective specif c activity of the compound, an increase in the sensitivity of the animal scanner relative to human PET scanners, or both, will be required if new radiopharmaceuticals are to be evaluated in animal models by external imaging without these limitations. Although probably not suff cient for mice, FCWAY PET scanning in rats is possible with presently attainable specif c activities and the sensitivity of contemporary small animal PET scanners.

\section{Appendix}

The relationship between human and rodent imaging can be established by requiring that the same coincidence rate be observed from a rodent imaging "voxel" as from the human imaging voxel, where "voxel" is def ned as the cube of the (isotropic) spatial resolution of the imaging device. If the subscript " $r$ " refers to rodent and the subscript " $h$ " refers to human, then equal voxel activities will occur when:

$$
S_{r} C_{r} V_{r} \rho_{r} \exp \left[-u T_{r}\right] E_{r}=S_{h} C_{h} V_{h} \rho_{h} \exp \left[-u T_{h}\right] E_{h}
$$

where $S=$ specif c activity $(\mu \mathrm{Ci} / \mathrm{gm}), C=\mathrm{drug}$ (radiopharmaceutical) concentration (gm/gm), $V=$ voxel volume (cc), $\rho=$ tissue density $(\mathrm{gm} / \mathrm{cc}), u=$ linear attenuation coeff cient of tissue at $511 \mathrm{keV}(1 / \mathrm{cm}), T_{h}$ and $T_{r}$ (in centimeters) are the characteristic thicknesses of tissue across the body at the location of the voxel of interest, and $E$ is the fraction of coincidence pairs detected by the animal and human PET scanners compared to the number emitted from the respective voxels.

Solving Eq. (1) for $C_{r}$ gives

$$
C_{r}=\left[S_{h} / S_{r}\right]\left[V_{h} / V_{r}\right]\left[E_{h} / E_{r}\right] \exp \left[-u\left(T_{h}-T_{r}\right)\right] C_{h}
$$

where we have assumed that the density of tissue in human and rat is the same. It is of interest to evaluate this expression for several relevant cases: when the same drug preparation is used in the rat as in the human, i.e. when $S_{r}=S_{h}$ and in the case when $C_{r}=C_{h}$. 
In either of these cases, the ratio of voxel volumes varies approximately as the ratio of body masses so that the volume ratio can be replaced by the ratio of human to rat body masses: 70,000 gm/250 gm $=280$. If the transverse dimension of the human head is taken to be $18 \mathrm{~cm}$ and the rat head $3 \mathrm{~cm}$, and the linear attenuation coeff cient to be $0.08 / \mathrm{cm}$, then the exponential term in Eq. (2) takes on the value: 0.3. In addition, current generation small animal PET scanner possess detection eff ciencies not terribly different from human PET scanners so the eff ciency ratio can also be set equal to unity. In the frst case, therefore, the expression for the rat drug concentration becomes:

$$
\begin{aligned}
C_{r} & =(280)(0.3) C_{h} \\
C_{r} & =(84) C_{h}
\end{aligned}
$$

That is, if the same drug, i.e., same specif c activity, is used to image both rat and human, the drug concentration in the target tissue of the rat will be 84 times higher than in the human subject to obtain the same statistical image quality in the same imaging time and same relative degree of resolution as in the human study.

In the second case, the condition necessary to make the concentrations equal in both rat and human is

$$
\left(S_{r} E_{r}\right) /\left(S_{h} E_{h}\right)=84
$$

This relation implies that in order to make the concentrations equal, the specif c activity-detection eff ciency product for the rat study must be some 84 times greater than for the human study. This elevated ratio can be achieved by increasing the specif $\mathrm{c}$ activity of the compound used in the rat study by this factor, by increasing the sensitivity of the small animal PET scanner by this factor or by increasing both such that the product of specif c activity-detection eff ciency is 84 for the rat study compared to the human study. Given that the detection eff ciency of small animal PET scanners cannot be improved realistically by more than a factor of about $f$ ve relative to human PET scanners, it follows that even in the rat some increase (a factor of 17 in this case) must be made in specif c activity if the rat and human studies are to be performed at identical drug concentrations.

If the condition expressed in Eq. (4) is not met and the specif c activity-detection eff ciency ratio is the same in rats and humans, the total amount of radioactivity administered to the rat for imaging equivalency is given by the equation:

$$
\begin{aligned}
& A_{r}=84 A_{h}\left[V_{r} / V_{h}\right]=(84)(250 / 70,000) A_{h} \\
& A_{r}=0.3 A_{h}
\end{aligned}
$$

where $A$ is the total injected activity. Therefore, human and rat equivalency can be obtained if the rat receives $30 \%$ of the human dose. This dose, evidently, is not terribly different from the human dose, a result contrary to intuition and at odds with conventional allometry, which would predict a 280 -fold reduction in injected activity for the rat. The cal- culation here assumes that when a human is given a humanappropriate dose, the tracer does not saturate the human system. The calculation also assumes that the duration of the human imaging study must also be matched by the animal study. Since the total number of recorded coincidences determines the statistical precision of the measurement of voxel activity, not just the coincidence rate, these conditions can be relaxed depending on the temporal behavior of the tracer. For example, a tracer that goes to the brain and remains $f x e d$ there can be imaged for extended periods at least in principle. In such a case, the dose and tissue concentration could be lowered in the rat by giving less activity but imaging for a longer time. The equivalency condition we have used here requires that tissue concentration, effective spatial resolution and total imaging time for the rat study are identical to the human study and that the human study exhibits satisfactory statistical precision of measurement under these conditions.

\section{References}

[1] Russell WMS, Burch RL. The principles of humane experimental technique. London, England: Metheun and Co. Ltd., 1959.

[2] Boulton AA, Baker GB, Butterworth RF. Animal models of neurological disease, I. neorodengenerative diseases. In: Neuromethods. Totowa, NJ: Humana Press, 1992

[3] Shinbane JS, Wood MA, Jensen DN, Ellenbogen KA, Fitzpatrick AP, Scheinman MM. Tachycardia-induced cardiomyopathy: A review of animal models and clinical studies. Journal of the American College of Cardiology 1997;29(4):709-715.

[4] Hiai H, Yamada Y, Abujiang P, Lu L, Kamoto T, Tsuruyama T. Genetic and epigenetic susceptibility to endogenous retrovirus-induced lymphomas in SL mice. Prog Exp Tumor Res 1999;35:64-77.

[5] Moody TW, Leyton J, Unsworth E, John C, Lang L, Eckelman WC. (Arg15, Arg21) VIP: evaluation of biological activity and localization to breast cancer tumors. Peptides 1998;19(3):585-92.

[6] Siegel S, Vaquero JJ, Aloj L, Seidel J, Jagoda E, Gandler WR, et al. Initial results from a PET/Planar small animal imaging system. IEEE Trans Nucl Sci 1999;46:571-5.

[7] Hamacher K, Coenen HH, Stocklin G. Eff cient stereospecif c synthesis of no-carrier-added 2-[ $\left.{ }^{18} \mathrm{~F}\right]-$ f uoro-2-deoxy-D-glucose using aminopolyether supported nucleophilic substitution. J Nucl Med 1986;27(2):235-8.

[8] Namavari M, Satyamurthy N, Phelps ME, Barrio JR. Synthesis of $6-\left[{ }^{18} \mathrm{~F}\right]$ and $4-\left[{ }^{18} \mathrm{~F}\right] \mathrm{f}$ uoro-L-m-tyrosines via regioselective radiof $\mathrm{u}-$ orodestannylation. Appl Radiat Isot 1993;44(3):527-36.

[9] Lang L, Jagoda E, Schmall B, Vuong BK, Adams HR, Nelson DL, Carson RE, Eckelman WC. The Development of f uorine-18-labeled 5-HT1A antagonists. J Med Chem 1999;42(9):1576-86.

[10] Olasz EB, Lang L, Seidel J, Green MV, Eckelman WC, Katz SI. Fluorine-18 labeled mouse bone marrow-derived dendritic cells can be detected in vivo by high resolution projection imaging. J Immunol Methods 2002;260(1-2):137-48.

[11] Zingone A, Seidel J, Aloj L, Caraco C, Vaquero JJ, Jagoda EM, Chou JY, Green MV, Eckelman WC. Monitoring the correction of glycogen storage disease type 1a in a mouse model using [(18)F]FDG and a dedicated animal scanner. Life Sci 2002;71(11):1293-301.

[12] Wolkersdorfer GW, Bornstein SR, Higginbotham JN, Hiroi N, Vaquero JJ, Green MV, Blaese RM, Aguilera G, Chrousos GP, Ramsey WJ. A novel approach using transcomplementing adenoviral vectors for gene therapy of adrenocortical cancer. Horm Metab Res 2002; 34(6):279-87. 
[13] Lambrecht R, Eckelman W, editors. Animal models in radiotracer design. New York, NY: Springer Verlag, 1983.

[14] Shimoji K, Kiesewetter DO, Esaki T, Itoh Y, Sokoloff L, Eckelman WC. Effects of P-TZTP on local cerebral blood fow in rat brain. J Nucl Med 2001;42(5):936.

[15] Bolo NR, Brennan KM, Jones RM, Budinger TF. Fluorodeoxyglucose brain metabolism studied by NMR and PET. New York, NY: Annuls of the New York Academy of Sciences 1987:508;451-9.

[16] Kanazawa Y, Yamane H, Shinohara S. 2-Deoxy-2-f uoro-D-glucose as a functional probe for NMR: the unique metabolism beyond its phosphate. J Neurochem 1966;66:2113-20.

[17] Barrio JR, Huang SC, Yu DC, Melega WP, Quintana J, Cherry SR, Jacobson A, Namavari M, Satyamurthy N, Phelps ME. Radiof uorinated L-m-tyrosines: new in-vivo probes for central dopamine biochemistry. J Cereb Blood Flow Metab 1996;16(4):667-78.

[18] Rahman MK, Nagatsu T, Kato T. Aromatic L-amino acid decarboxylase activity in central and peripheral tissues and serum of rats with L-DOPA and L-5-hydroxytryptophan as substrates. Biochem Pharmacol 1981;30(6):645-9.

[19] Hume SP, Gunn RN, Jones T. Pharmacological constraints associated with positron emission tomographic scanning of small laboratory animals. Eur J Nucl Med 1998;25(2):173-6.

[20] Khawaja X, Evans N, Reilly Y, Ennis C, Minchin MCW. Characterization of the binding of $\left[{ }^{3} \mathrm{H}\right] \mathrm{WAY} 100635$, a novel 5-hydroxytryptamine 1a receptor antagonist, to rat brain. J Neurochem 1995;64: $2716-26$.

[21] Selikson M, Gibson RE, Eckelman WC, Reba RC. Calculation of binding isotherms when ligand and receptor are in different volumes of distribution. Anal Biochem 1980;108(1):64-71.

[22] Motulsky H. Analyzing data with GraphPad prism. In: San Diego, CA: GraphPad Software Inc., 1999;333.

[23] Hall H, Lundkvist C, Halldin C, Farde L, Pike VW, McCarron JA, Fletcher A, Cliffe IA, Barf T, Wikstrom H, Sedvall G. Autoradiographic localization of $5-\mathrm{HT}_{1 \mathrm{~A}}$ receptors in the post-mortem human brain using $\left[{ }^{3} \mathrm{H}\right] \mathrm{WAY}-100635$ and $\left[{ }^{11} \mathrm{C}\right] \mathrm{WAY}-100635$. Brain Res 1997;745:96-108.

[24] Meikle SR, Eberl S, Fulton RR, Kassiou M, Fulham MJ. The inf uence of tomograph sensitivity on kinetic parameter estimation in positron emission tomography imaging studies of the rat brain. Nucl Med Biol 2000;27(6):617-25. 